\title{
UM OLHAR COMPARATIVO SOBRE A "QUESTÃO TARTÉSSICA
}

Pedro Albuquerque ${ }^{1}$

\section{RESUMO}

Este artigo analisa a "questão tartéssica" a partir de um olhar comparativo, utilizando dados das fontes escritas pré-romanas, do registo arqueológico e alguns casos da História Africana Moderna e Contemporânea (sécs. XV - XX). Este tipo de investigação pode proporcionar um novo entendimento dos processos de transformação identificáveis no registo arqueológico do SW da Península Ibérica (sécs. IX - VI a.C.), ao analisar, por exemplo, a violência nos contatos interculturais e na construção e manipulação das relações de pertença, comparando estes processos históricos africanos com a documentação escrita e arqueológica. Com esta metodologia é possível obter uma noção das diferenças entre um contexto de relação comercial e outro, de relação colonial, em termos de visibilidade arqueológica.

PALAVRAS-CHAVE: Tartessos; Método comparativo; Colonizações; Contatos interculturais; Violência.

\section{ABSTRACT}

This paper analyzes the "Tartessian question" by a comparative point of view, dealing with the pre-roman written sources, the Archaeological record and, finally, some African history cases of the Modern and Contemporary Era (15th - 20th centuries). This kind of investigation can lead us to a new understanding of the transformation processes that can be identified in the Archaeological data (between 9th and 6th centuries BC) of the Southwestern Iberia. This perspective deals, e.g., with violence in the context of intercultural contacts and changing identities, by comparing these African historical processes with both written and archaeological sources, leading us to have a close look to the differences between commercial and colonial presence in terms of material results and territoriality.

KEYWORDS: Tartessos; Comparative method; Colonizations; Intercultural contacts; Violence

\section{RESUMEN}

Este artículo analiza la "cuestión tartésica" desde una perspectiva comparativa, utilizando datos procedentes de las fuentes escritas prerromanas, del registro arqueológico y de algunos casos de la Historia Moderna y Contemporánea de África (siglos XV - XX). Este tipo de investigación puede proporcionar una nueva comprensión de los procesos de cambio

\footnotetext{
${ }^{1}$ (Uniarq/ CLEPUL, Universidade de Lisboa). R. Sol, 7 R/C 2680-369 Catujal (Portugal) (00351) 930534780.skapedroalbuquerque@gmail.com
} 
identificables en el registro arqueológico del SW peninsular (siglos IX - VI a.C.), al analizar, por ejemplo, la violencia en los contactos interculturales y en la construcción/manipulación de las relaciones de pertenencia a partir de la comparación de procesos históricos africanos con la documentación escrita y arqueológica. Con esta metodología puede obtenerse una idea adecuada acerca de las diferencias en términos de visibilidad arqueológica entre contextos de relación comercial y contextos de relación colonial.

PALABRAS CLAVE: Tartessos; Metodología comparativa; Colonizaciones; Contactos interculturales; Violencia.

À Lúcia, por tudo.

\section{CONSIDERAÇÕES PRÉVIAS}

Poucos temas da Proto-história da Península Ibérica despertaram tanto interesse como Tartessos. Desde, pelo menos, o séc. XVI, este nome ganhou uma importância extraordinária como referente da História peninsular, bem como as personagens associadas a esse território. A partir dos trabalhos de A. Schulten (1945), Tartessos passou a ser vista como a primeira civilização ocidental, cujos vestígios foram freneticamente procurados por este investigador alemão, mas sem sucesso. A localização da cidade perdida foi perdendo, gradualmente, importância a partir do momento em que se registou uma reação nacionalista às propostas schultenianas (o autor pensava que os povos ibéricos seriam incapazes de construir dita civilização), encabeçada por Maluquer de Motes (1955), importando a partir desse momento a análise do processo de transformação das sociedades indígenas do Bronze Final.

A formação deste "indigenismo" de Tartessos é indissociável da afirmação de um "problema arqueológico", consolidado num congresso realizado em 1968 em Jerez de la Frontera (AAVV, 1969). A Arqueologia acabou por tomar a dianteira de um problema que, anteriormente, pertencia ao domínio da hermenêutica dos textos da Antiguidade. Tal não significa que se tenha logrado um discurso mais objetivo: pelo contrário, a construção de um significado arqueológico para esta entidade baseou-se num nome transmitido pelas fontes e na convição de que Tartessos mergulhava as suas raízes no Bronze Final, sem que se registem textos que permitam caracterizar a filiação "étnica" destas populações. Foi a partir deste momento que a bibliografia arqueológica começou a reproduzir, não raras vezes de 
forma acrítica, a definição de "tartéssico" para sítios, comunidades e materiais (ÁLVAREZ, 2005: passim; ALBUQUERQUE, 2014: 130 - 148).

Os avanços nos métodos arqueológicos serviram, neste sentido, os apriorismos construídos ao longo das décadas de 50 e 60 do séc. XX, variando somente o questionário sobre o registo material. Por exemplo, os anos 70 foram marcados pela adoção da New Archaeology e, consequentemente, por reflexões sobre o registo funerário enquanto manifestação de diferenças entre os membros de uma sociedade e de aculturação seletiva. O discurso centralizou-se, portanto, nas chamadas elites tartéssicas e nas transformações que estas levaram a cabo, no contexto de uma "orientalização" impulsionada (exclusivamente) pelo comércio. Esta perspectiva valorizou a ideia preconcebida de que os Tartéssios - indígenas viviam nos territórios do interior e os Fenícios - comunidades exógenas ocupavam as regiões costeiras (cf. BELÉN e ESCACENA, 1997: 110ss.; ÁLVAREZ, 2005: passim, com uma importante reflexão historiográfica).

Esta imagem foi determinante para a análise dos vestígios arqueológicos identificados por G. Bonsor no final do séc. XIX e início do séc. XX na área de Los Alcores de Carmona (BONSOR, 1997). A localização interior desta área levou este investigador a considerar que as necrópoles testemunhavam uma colonização agrícola levada a cabo por grupos orientais ${ }^{2}$. Mais tarde, estes sítios arqueológicos foram considerados tartéssicos pelas mesmas razões (AMORES, 1982), na sequência da descoberta de um suposto "fundo de cabana" em El Carambolo, nas imediações de Sevilha, em 1958 (CARRIAZO, 1980) e da multiplicação das chamadas "escavações estratigráficas" nesta mesma zona (CARRIAZO e RADDATZ, 1960; recentemente, PELLICER e AMORES, 1985). A multiplicação de cortes estratigráficos servia o propósito de obter dados que permitissem caracterizar a "evolução" da "cultura tartéssica" e uma cronologia para os materiais aí identificados ${ }^{3}$.

Apesar do interesse destes dados, não deixa de chamar a atenção o fato de se verificar a tendência para dar um conteúdo arqueológico às propostas indigenistas, aproveitando o vazio deixado pelas investigações de Schulten. Manteve-se, neste contexto, uma ideia que acabou por ser transversal à investigação histórica, filológica e arqueológica

\footnotetext{
${ }^{2}$ Há já alguns anos, estudos paleogeográficos permitiram afirmar que a desembocadura do Guadalquivir estava na área de Sevilha (ARTEAGA, SCHULZ \& ROOS, apud BELÉN e ESCACENA, 1997: 109 - 110), contrariando a ideia de interioridade destes sítios arqueológicos. Neste contexto, veja-se a opinião de J. Sanmartín (1994: 230) sobre o topónimo Hispalis.

${ }^{3}$ Ditas escavações estratigráficas não são aqui assinaladas com o desejado detalhe, importando somente referir a sua importância para a construção e consolidação de uma ideia preconcebida.
} 
do séc. XX: que Tartessos era uma entidade diferente dos "fenícios". Esta polarização só muito recentemente foi posta em causa, após uma cuidadosa análise historiográfica das representações de Tartessos a partir do séc. XVI (ÁLVAREZ, 2005; 2007; 2009).

Estas últimas propostas valorizaram, sobretudo, a documentação escrita e o pensamento subjacente ao discurso arqueológico. O registo material pode, neste sentido, ter outras leituras que deem visibilidade à interação cultural, à hibridação (contrariando a ideia polarizante que presidiu aos estudos anteriores), bem como a processos de transformação resultantes de cenários históricos de violência. Esta análise é possível com o recurso a uma metodologia comparativa que incide sobre outros contextos históricos em que se verificou uma relação desigual entre sociedades diferentes (p.ex., entre Africanos e Europeus a partir do séc. XV). Com este ponto de partida, colocam-se algumas questões sobre as fontes escritas e o registo arqueológico. A favor desta opção está, p.ex., o fato de estarmos perante processos históricos que, embora sejam muitomais recentes, têm reflexo na documentação escrita e no registo material, o que de certa forma facilita a elaboração deste questionário.

O presente trabalho pretende discutir este último ponto, partindo de três aspectos: o problema das representações das comunidades proto-históricas peninsulares em geral, e de Tartessos em particular, nas fontes escritas; o problema do registo arqueológico; a leitura destes dados à luz de um "olhar comparativo sobre a questão tartéssica". Esta contribuição procura sintetizar um estudo mais amplo que resultou na elaboração de uma dissertação recentemente apresentada (ALBUQUERQUE, 2014).

\section{TARŠIŠ/ TARTESSOS E TARTÉSSIOS NAS FONTES ANTERIORES AO SÉC. III A.C.}

As referências veterotestamentárias a Taršiš são um ponto de partida para compreender os problemas associados à aparição da Península lbérica nos textos elaborados no Mediterrâneo Central e Oriental ${ }^{4}$. Este nome foi associado ao Extremo Ocidente, particularmente a Tartessos, a partir, sobretudo, do séc. XVII, desafiando-se a perspectiva, comum na centúria anterior, de que Tubal fora o primeiro povoador da Península lbérica. Com isto, passagens com as que referem as viagens de Hiram e

\footnotetext{
${ }^{4}$ É possível que a estela de Nora, identificada na sarda Tharros (CIS, I.144), seja a menção mais antiga a esta região (ou cidade?), mas as questões que se lhe colocam ao nível da leitura e tradução merecem um desenvolvimento que não pode ser aqui mantido (cf. ALBUQUERQUE, 2014: 114ss.).
}

\begin{tabular}{|l|l|l|l|l|l|l|} 
(C) Rev. Arqueologia Pública & Campinas, SP & v.9 & Nº.1(11) $^{\circ}$ & p.73-97 & Jan-Jun/2015 & ISSN 2237-8294
\end{tabular}


Salomão a Taršiš ganharam outro interesse, sobretudo para destacar a importância de Tartessos no contexto do comércio mediterrânico ou a criação de um termo técnico, navios de Taršiš, aplicável a embarcações que percorriam grandes distâncias (cf. KOCH, 2003: 49ss.). Apesar de todos os comentários que podem ser feitos a estes textos, não há dúvida de que são referências extremamente vagas a um território ocidental, faltando pormenores sobre a sua localização, ou mesmo sobre a origem e composição da sua população.

As tentativas de caracterização "étnica" de Taršiš incidiram, p.ex., sobre a leitura etimológica do topônimo. A sequência consonântica Trt-/ Trs- foi, neste sentido, determinante, uma vez que foi identificada em vários lugares da Península lbérica e serviu de argumento para provar que esta população era indígena e que deu a si mesma um nome que se reproduziu nos textos antigos a partir de Hiram até ao período helenístico e romano (ibid.: passim).

O fato de um nome ser reproduzido na documentação escrita ao longo de vários séculos não pressupõe que a sua caracterização seja a mesma ("Luso-africanos": v. infra), independentemente da origem da designação. Esta discussão estender-se-ia aqui à toponímia. Esta, para J. Sanmartín (1994) é menos permeável à transformação que os antropônimos, o que de certo modo pode justificar a continuidade dos nomes de lugar, ou mesmo a sua adaptação a novos contextos linguísticos (cf. ALBUQUERQUE, 2014: 19ss., com discussão sobre este tema). Este critério não é suficiente para desenvolver uma aproximação rigorosa aos processos identitários, sobretudo quando não se pretende abraçar uma metodologia histórico-culturalista ou, se preferirmos, essencialista.

A construção de uma "toponímia tartéssica" responde aos mesmos princípios que o estudo do registo arqueológico com base no apriorismo indigenista. Podemos defender este ponto de vista a partir da imagem que as fontes escritas nos transmitem, salientando que muitos desses nomes de lugar foram transmitidos em épocas muito tardias e que a designação de "tartéssica" resulta de um critério locacional: os topônimos inscritos nesta categoria estão distribuídos ao longo do Guadalquivir. Por esta razão, o uso destas informações na análise do registo arqueológico requer muita prudência.

Esta relação é o ponto de partida para a discussão sobre as fontes gregas que mencionaram este nome. Numa passagem da Geografia de Estrabão, assinala-se que Estesícoro de Himera associou o nascimento de Gérion a uma gruta junto à nascente do rio Tartessos, interpretado pelo geógrafo de Amásia como o Guadalquivir (fr. 184 PMG/ Str. 3.2.11; cf. Page, 1973). Antes disso, Heródoto assinalou que a captura das vacas de Gérion, ou o Décimo trabalho de Héracles, estava associado a Gadir, i.e., à ilha Erítia (Hdt. 4.8). A associação entre uma personagem como Gérion e o nascimento junto à nascente de 
uma linha de água é, no essencial, um topos literário, o que talvez explique o uso de Tartessos como hidrônimo num contexto em que, provavelmente, se pretendia justificar a colonização de Himera através das figuras de Gérion e do herói "civilizador" (ALBUQUERQUE, 2014: 117 - 118; FRANZEN, 2009).

A preocupação deste discurso não é, como parece óbvio, produzir uma representação precisa e rigorosa de um território do Extremo Ocidente. A ideia de riqueza que é transmitida no poema estesicoriano (i.e., as vacas e os pastos de Gérion) parece ecoar num outro fragmento, desta vez de Anacreonte de Theos (fr. 361 PMG/ Str. 3.2.14), no qual o poeta afirmava que "não quereria nem o corno de Amalteia nem reinar cento e cinquenta anos em Tartessos". O geógrafo de Amásia interpretou isto como uma menção a Argantónio, o famoso "rei dos tartéssios" que reinara oitenta dos seus cento e vinte anos de vida (Hdt. 1.163). Apesar do interesse desta possível relação, é evidente que a longevidade estaria associada à abundância e a uma vida despreocupada, não contradizendo em nenhum momento a associação dos confins do mundo a riquezas e a seres extraordinários.

Ocupar-nos-emos de Argantónio um pouco mais adiante. Por agora importa referir que o texto de Hecateu de Mileto, também lacunar, mencionou em várias ocasiões o nome de Tartessos, identificando-o (tal como, provavelmente, em Hdt. 1.163) como uma região na qual se integravam duas cidades (Elibirge e lbila). Estas informações fazem parte da obra de Estêvão de Bizâncio (séc. VI) que, como se sabe, tinha interesses gramaticais e filológicos.

Um episódio, também recolhido por Heródoto na sua enquête, tem como protagonista principal Colaios, um navegante sâmio que, no contexto da fundação de Cirene, terá chegado a Tartessos depois de ter sido afastado da sua rota pelo vento do levante. A referência a um "porto inexplorado" indicia que, pelo menos em Samos, Tartessos era um topônimo associado a um território localizado a Ocidente das Colunas de Héracles (i.e., Estreito de Gibraltar). Como tal, pertenceria a um âmbito menos "racionalizado" e mais ligado a paisagens fabulosas, tal como foi assinalado nos restantes casos.

Só Hecateu parece representar uma exceção a esta regra, talvez porque a sua obra teve objetivos que não coincidiam com os outros autores. O fato de, p.ex., Tartessos ter sido mencionado por Heródoto não significa que estas informações sejam consistentes, uma vez que o autor, manifestamente, assinala o seu desconhecimento do Ocidente (Hdt. 3.115) e não se interessou muito por este território: o primeiro texto (1.163) explica a construção de uma muralha na Foceia e o segundo (4.152) está associado à fundação de Cirene. Ambos resultam da recolha de tradições orais e apresentam traços identificáveis na 
poesia (cf. ALBUQUERQUE, 2010). Ou seja, Tartessos acabou por apresentar características que, provavelmente, não fariam sentido numa obra como a de Hecateu de Mileto, não obstante o fato de estarmos perante um conjunto de fragmentos e não de uma obra completa. Note-se, neste sentido, que a informação de Estêvão de Bizâncio sobre Tartessos não parece ter sido inspirada pelo autor milésio: para aquele autor, é uma região

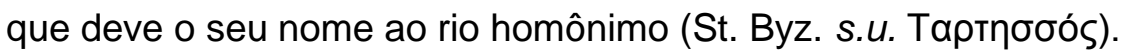

$\mathrm{O}$ etnônimo, por seu turno, parece surgir nas obras posteriores ao séc. $\mathrm{V}$ a.C., tendo em Heródoto (1.163) e Herodoro ( $F G r H, 31$, Fr. 2a) os testemunhos mais antigos. Tanto Teopompo como Éforo, autores do séc. IV a.C. e discípulos de Isócrates, mencionaram, possivelmente, na sua obra, os "tartéssios". Os três últimos são conhecidos pelos fragmentos transmitidos por outros autores, mas permitem assinalar uma tendência para referir o etnônimo em vez do hidrônimo, do topônimo ou do corônimo (ÁLVAREZ, 2009; ALBUQUERQUE, 2013). Além disso, é fundamental salientar que o desconhecimento da totalidade das suas obras impede uma avaliação rigorosa de, pelo menos, três tipos de informação: (1) o contexto em que os Tartéssios surgem nos textos, e a sua importância para a obra em geral; (2) o conhecimento que os autores tinham do Extremo Ocidente; (3) os critérios de individualização que presidiram à transmissão do etnônimo.

Esta última questão inspirou a necessidade de analisar os textos na óptica dos conceitos utilizados e das situações em que foram aplicados (ALBUQUERQUE, 2014: 62ss.). O estudo desta terminologia permite verificar, p.ex., que um ethnos em Heródoto não pressupõe, necessariamente, a existência de um grupo homogêneo do ponto de vista "étnico", mas sim de um conjunto de indivíduos que se definem em torno de uma mesma relação de pertença. É possível, ainda que tal não seja explícito, que Heródoto se tenha referido aos Tartéssios como um ethnos, mas não podemos deixar de notar, tal como Jones (1996), que o uso do termo basileus implica o uso de um genitivo que assinale a existência de um povo e não de um território, o que de certo modo pode justificar o uso de um etnônimo.

Para Herodoro, os Tartéssios são uma "tribo" (phylê) integrada no povo (génos) ibérico $(F G r H, 31$, fr. 2a), mas a falta de conhecimentos mais precisos sobre os seus Tratados sobre Hércules é um obstáculo à compreensão dos conceitos que o autor utilizou nesta obra. Para além disso, desconhece-se a cronologia desta informação (ÁLVAREZ, 2009). Trata-se, no entanto, da única referência explícita a uma phylê, o que não acontece noutros fragmentos posteriores de Teopompo e de Éforo, ambos discípulos de Isócrates.Estes dois autores do séc. IV a.C. transmitiram, igualmente, um etnônimo Tartéssios, de acordo com o texto de Estêvão de Bizâncio.

\begin{tabular}{|l|l|l|l|l|l|l|}
\hline () Rev. Arqueologia Pública & Campinas, SP & v.9 & No.1(11) $^{\circ}$ & p.73-97 & Jan-Jun/2015 & ISSN 2237-8294 \\
\hline
\end{tabular}


Teopompo foi autor de uma obra dedicada à vida de Filipe II, o que por um lado delimita o âmbito cronológico desta referência e, por outro, leva a perguntar qual o interesse que o autor tinha nestes "tartéssios" para assinalar que eram vizinhos da região (chôra) de Massia no seu Livro 43 (FGrH 155, fr. 200/ St. Byz., s.u. Massía) e do povo ibérico (ethnos) dos Tletes, no Livro 45 (FGrH 155, fr. 201/ St. Byz., s.u. Tlêtes). Pode, eventualmente, tratar-se de uma digressão do autor, mas um exercício de especulação sobre este tema não levaria a conclusões importantes (cf. ÁLVAREZ, 2009; ALBUQUERQUE, 2013).

Apesar de ser mais conhecido, sobretudo pelo fato de ter sido mencionado por várias vezes na Geografia de Estrabão, Éforo escreveu uma obra com uma cronologia bem mais alargada, i.e., entre o retorno do Heraclidas e o seu próprio tempo (c. 1068 e 341/ 340 a.C.: FGrH 70, t 1, 8 e 10, apud SCHEPENS, 1977: 95). Esta situação levou o autor a optar pela genealogia (cf. Plb. 9.1.4) e pela descrição dos "eventos (ou práticas) do mundo" (koinai praxeis), surgindo neste âmbito uma referência aos tartéssios como um grupo que transmitiu informações sobre os movimentos dos Etíopes no Norte da África ( $F G r H$ 79, fr. $128 /$ Str. 1.2.26). Outras passagens revelam que Éforo se referiu outras vezes a territórios ocidentais, nomeadamente ao Promontório Sacro (Str. 3.1.4; cf. Albuquerque, 2014: 206ss.) e a Gadir (ou à ilha Erytheia: Plin., N.H., IV, 120), o que permite afirmar que o Ocidente teve alguma importância na obra eforiana. Para M. Álvarez (2007; 2009), estes tartéssios seriam, na verdade, gaditanos.

As fontes posteriores ao séc. III a.C. revelam outros tipos de preocupações e, consequentemente, outro rigor que era dispensável nas fontes mais antigas, devido sobretudo aos interesses da expansão romana no Ocidente. É a partir desse momento que começam a surgir textos mais descritivos, elaborados por indivíduos que conheceram, de fato, os territórios que descrevem (cf. García Fernández, 2012). Muitos dos fragmentos citados (p.ex., Estesícoro, Anacreonte, Éforo) foram transmitidos nestas obras, em parte como reflexo de estudos que procuravam fontes sobre a história dos territórios conquistados e integrados num novo cenário histórico. Apesar do maior rigor que se assinala a obras como a de Políbio, Estrabão, Plínio - o - Velho, entre outros, não podemos deixar de considerar que o uso das suas informações para a análise de contextos históricos mais antigos requer muita prudência.

Em todo o caso, Taršiš/ Tartessos faz parte de tradições vinculadas ao mundo ocidental, conhecido no Mediterrâneo por intermédio das viagens ditas "fenícias" ou, se preferirmos, "orientais". A ausência destes Fenícios ou de Fenícios ocidentais nas fontes associadas àquela entidade tem vindo a ser justificada das mais variadas formas, destacando-se em primeiro lugar o uso desta ausência como argumento que prova a 
polarização, i.e., que Tartessos não podia ser uma entidade vinculada ao mundo "fenício". No entanto, parece relativamente evidente que o argumento poderia servir para demonstrar o inverso, i.e., que dita ausência é já o resultado de uma associação e que esta dispensa uma referência explícita. Isto é visível na discussão sobre os textos de Heródoto, e adquire contornos especialmente interessantes quando as atenções se voltam para a interpretação arqueológica do chamado "mundo tartéssico".

\title{
3. TARŠIŠ/ TARTESSOS E TARTÉSSIOS: PERSPECTIVAS ARQUEOLÓGICAS
}

\begin{abstract}
Ahora se ha levantado una punta del velo de esta gran incógnita, y se ha empezado a rellenarse esta gran laguna. [...] Lo que parecían exageraciones poéticas se han hecho realidades arqueológicas. Ahora sabemos por qué era fuerte y podía ser magnánimo Argantonio. (CARRIAZO, 1980: 178, sobre El Carambolo)
\end{abstract}

La imagen que tenemos de Tartessos, tal como nos la han llegado las fuentes clásicas, no es más que una visión tardía y helenizada de un fenómeno cultural eminentemente protohistórico e indígena, cuya historia se desarrolla en el área del Bajo Guadalquivir y cuyas raíces se encuentran en las culturas locales de la edad del Bronce (AUBET, 1986: 58)

O estudo de uma entidade mencionada pelas fontes clássicas encontra como primeiro obstáculo um desfasamento entre o que esses textos transmitem e aquilo que se pretende, ou que se consegue, ver no registo arqueológico. Nenhum desses documentos tem como critério de individualização o uso de determinada cultura material, ou mesmo de uma língua, mas há aspectos que podem - e devem - ser considerados no momento em que se pretende estabelecer uma relação entre estes dois âmbitos de estudo. Em primeiro lugar, podemos destacar a questão cronológica, em que se analisam os materiais identificados com base nas informações das fontes para reflectir, p.ex., sobre o resultado arqueológico das menções a Taršiš no Antigo Testamento (=AT) no Ocidente (MEDEROS, 2006). Outro exemplo: a identificação, no Heraion de Samos, de pentes de marfim com clara origem ocidental (SCHAUENBURG, apud METZGER, 1967: 435; AUBET, 1978: 20-21), em níveis do séc. VII a.C., permitiu não só afinar a cronologia dos objetos identificados em solo peninsular, como também ter um ponto de partida para relacioná-los com a viagem de Colaios a Tartessos, ou mesmo para integrar a sua aparição numa hipótese de fuga de artesãos para o Ocidente neste período (A. BLANCO, apud AUBET, 1978: 19). Por seu turno, a identificação de cerâmicas gregas em Huelva gerou, igualmente, bastante entusiasmo e contribuiu para reforçar a ideia de que a área urbana onubense correspondia 
a Taršiš/ Tartessos (entre outros, OLMOS, 1989; GONZÁLEZ, 2004; CAMPOS e ALVAR, eds., 2013).

A imagem arqueológica de Tartessos, como vimos nas considerações prévias, nasce de uma tentativa de fornecer um conjunto de materiais que permitissem provar 0 indigenismo desta entidade, não obstante o inegável fato de que as fontes em nenhum momento assinalaram uma origem indígena ou exógena. No entanto, nem sempre é possível distinguir com clareza a fronteira entre estas entidades em termos arqueológicos, ou mesmo afirmar que estamos perante indígenas "orientalizados" ou "fenícios ocidentalizados", uma vez que ambas as situações seriam, no absoluto, possíveis em processos que envolvem, como muito possivelmente este, indivíduos de origens diversificadas (cf. HORTA, 2009: passim e os "Luso-africanos"), mais ainda em cronologias mais avançadas como, p.ex., o séc. VII a.C.

A referida polarização acabou por caracterizar o discurso arqueológico sobre a realidade dita "tartéssica", e como esta se diferenciaria da "fenícia": a planta oval/ circular frente à planta quadrada/ retangular das construções; a cerâmica manual frente à cerâmica a torno; presença de determinados objetos nos enterramentos (p.ex., urnas tipo "Cruz del Negro") como manifestações indígenas/ "tartéssicas"; ocupação do interior face a ocupação costeira; toponímia, etc. (BELÉN e ESCACENA, 1997; ALBUQUERQUE, 2014).

Não podemos deixar de salientar que se assiste a transformações significativas nas manifestações materiais das comunidades da atual Andaluzia. O desconhecimento, em muitos casos, do "antes" (cf. ESCACENA, 1995) pode ser, em si mesmo, um dado quando verificamos que se registam novas ocupações, tanto para a construção de estruturas destinadas ao culto, como para a implantação de necrópoles ou de núcleos habitacionais. É neste sentido que se insistiu na ideia de "aculturação" por parte das comunidades residentes que, a partir de um determinado momento, utilizaram objetos de prestígio (i.e., bens importados) como fonte de legitimação e reforço do seu poder, integrando-se nas rotas comerciais do Mediterrâneo (TORRES, 2002).

O "Orientalizante" é um conceito que surge neste contexto com o intuito de explicar estas transformações, marcando uma ideia de influência externa que, por sua vez, é resultado do que F. Moreno Arrastio classificou como "lógica do indígena fascinado" (2001: 105). Este mesmo autor defendeu uma perspectiva que apelidou de "pessimista" (1999; 2000; 2001) e, baseando-se em exemplos africanos, valorizou a introdução de armas nestes contextos (particularmente na Meseta espanhola) para propor a existência de cenários de violência (cf. WAGNER, 2005). 
Esta perspectiva merece, certamente, um debate mais profundo sobre o próprio registo arqueológico, particularmente sobre a interpretação da identificação de armas e carros em vários enterramentos, na medida em que poderia indiciar a formação de elites guerreiras que beneficiavam da violência ou que lucravam com ela. Para isso seria necessário olhar para a função destes objetos e matizar a ideia de que conferiam prestígio a quem os possuía.

Contrastando informações e ideias, é possível recorrer a outros exemplos históricos que, de certo modo, permitem lançar novas questões. No caso da Senegâmbia (sécs. XV-XIX) a formação dessas elites foi uma consequência direta do tráfico de escravos ou, por outras palavras, de incursões destinadas à captura de seres humanos em territórios interiores (cf. MACINTOSH, 2001: passim). Esta actividade provocou o abandono de algumas regiões e o súbito crescimento de espaços habitacionais, uma vez que provocou alterações significativas nos padrões de ocupação dos territórios. Ou seja: as populações promovem a integração num sistema ou protegem-se dele.

Esta, de um modo geral, não é uma imagem recorrente da "arqueologia tartéssica". Num brilhante trabalho de referência, publicado há alguns anos, M. Torres Ortiz (2002) procurou expor no seu discurso, aliás muito coerente, o percurso que comentávamos antes: a integração dos "Fenícios" na longue durée indígena e a imagem de um sistema já consolidado antes da chegada de novos elementos orientais. O foco desta análise é, claro, o desenvolvimento social no sentido da complexificação e da integração de elementos orientais no quotidiano das populações indígenas. Acompanhando a sua reflexão por um bem estruturado acervo material (algo que marca, igualmente, os seus trabalhos mais recentes), este investigador integra-se numa linha de estudos que valorizam o papel do indígena no seu percurso histórico.

A análise das fontes escritas nesta perspectiva de investigação é secundária, mas suficientemente importante para a construção de uma imagem histórica que assume, muitas vezes sem o esperado sentido crítico, que as fontes gregas se referiam a populações de cariz marcadamente indígena. Podemos também questionar se esses "indígenas" do Bronze Final são os mesmos que são mencionados, alguns séculos mais tarde, pelos autores gregos que tivemos oportunidade de assinalar. Propôs-se também que a toponímia, definida pela investigação linguística como "indígena" e denominada (por convenção) "tartéssica", seria também um indicador étnico seguro para demonstrar a extensão do território desta entidade (TORRES, 2005). Entrevê-se aqui uma aparente relação, implicitamente assumida, entre língua, cultura material e povo, que deve ser discutida (ALBUQUERQUE, 2014: 19ss).

\begin{tabular}{|l|l|l|l|l|l|l|}
\hline (C) Rev. Arqueologia Pública & Campinas, SP & v.9 & Nº.1(11) $^{\circ}$ & p.73-97 & Jan-Jun/2015 & ISSN 2237-8294
\end{tabular}


Estes aspectos, como se mencionou, têm vindo a ser criticados por outras vertentes da investigação, que incidem sobre a possibilidade de que esses "tartéssios" das fontes sejam, efetivamente, aqueles que são apelidados de "fenícios ocidentais" (entre outros, ÁLVAREZ, 2005; 2007; 2009). Este debate tem tanto de importante como de necessário, uma vez que obriga a refletir sobre as grandes lacunas das propostas anteriores, aceitas na maioria dos casos sem qualquer discussão, e propor novos caminhos de reflexão ${ }^{5}$. A comparação com outros cenários históricos é um desses caminhos, sem que para isso seja necessário deixar de defender que o "indígena" é um agente fundamental da transformação do seu processo histórico.

\section{UM OLHAR COMPARATIVO SOBRE TARTESSOS}

A expansão europeia a partir do séc. XV colocou em contato populações que se desconheciam mutuamente, conduziu a um aumento exponencial de conhecimentos geográficos, a uma melhoria das técnicas de navegação e, sobretudo, provocou impactos significativos nas sociedades em contato (sistemas econômicos, políticos, etc.). Não é possível comparar, em termos de dimensão, este processo com a expansão "fenícia" no Mediterrâneo, mas ambos colocam problemas semelhantes, nomeadamente a produção de representações e as consequências dos contatos no quotidiano dos grupos envolvidos.

As representações europeias do Africano são pautadas por critérios de observação que determinam, p.ex., a individualização de um grupo face a outros, ou mesmo as características que o observador pretende identificar nos grupos que representa (religião, vestuário, alimentação, recursos naturais, práticas econômicas, etc.), muitas vezes com o intuito de marcar a sua diferença, ou justificar a sua ideia de superioridade. A preocupação do discurso não é, portanto, transmitir a imagem que os outros têm de si próprios, é formular uma mensagem que deve ser compreendida pelo receptor. Estas afirmações levam a pensar que o discurso é o espelho do contexto histórico de quem o produz, não das comunidades representadas, embora seja possível defender, como J. Horta (1995), que estas representações fazem parte da história dos contatos.

No caso das fontes clássicas em geral, e das referências a Tartessos em particular, as questões que se colocam são, sensivelmente, as mesmas. Não há qualquer texto que

\footnotetext{
${ }^{5}$ Um exemplo eloquente nesse sentido é o fato de se interpretar sítios arqueológicos como manifestações de contatos entre comerciantes (identificados com os orientais) e elites indígenas, mesmo que os dados não permitem tecer grandes considerações. Ou seja, não são requeridas provas materiais para demonstrar esse apriorismo.
}

\begin{tabular}{|l|l|l|l|l|l|l|}
\hline (C) Rev. Arqueologia Pública & Campinas, SP & v.9 & N $^{\circ} .1(11)$ & p.73-97 & Jan-Jun/2015 & ISSN 2237-8294
\end{tabular}


pretenda apresentar uma descrição destas comunidades, nem mesmo definir os critérios que presidiram à sua individualização. Se "Tartéssio" é um etnônimo que se integra na definição grega de ethnos (cf. ALBUQUERQUE, 2014: 55-74), podemos verificar em que situações o termo é utilizado por cada autor. Esta análise só é possível no caso de Heródoto, mas uma leitura comparada das ocasiões em que o termo ethnos é utilizado é suficiente para afirmar que se aplica a grupos marcados pela heterogeneidade ou diversidade de origens, não pressupondo, necessariamente, uma ideia abstrata de coesão (cf. Hdt. 7.90, sobre a diversidade dos cipriotas). Os autores, note-se, nem sempre são os observadores, o que comprometeria, sem dúvida, a sua percepção dessas relações de pertença com um determinado grupo.

Não podemos, portanto, argumentar que Tartessos é uma entidade homogênea quando nem os conceitos utilizados na definição de grupos humanos (ethnos, genos e phylê) refletem tais perspectivas. Um exemplo bastante elucidativo é a designação de Luso - africano, uma vez que parece, à partida, falar por si própria enquanto grupo de indivíduos de origem portuguesa e africana. Porém, este grupo integrou, ao longo de, pelo menos, dois séculos, indivíduos de origens muito diversificadas, não só da Europa, mas também da África ${ }^{6}$. Ou seja, a designação fazia sentido num determinado contexto e refletia um sistema heterogêneo, não uma entidade impermeável (HORTA, 2009). Esta mobilidade de identidades cria um ponto de partida importante para analisar a "questão tartéssica" e os problemas que estas designações (sobretudo quando são criadas por um agente externo) colocam à investigação.

O segundo aspecto prende-se com as consequências dos contatos em termos de transformações ou adaptações mútuas. Uma vez mais, o estudo de processos históricos na África pode ser um ponto de partida para um olhar comparativo, destacando-se o caso de Angola, brilhantemente estudado por I. Castro Henriques (2004) num pequeno livro. Este estudo coloca questões de extrema importância que podem ser resumidas deste modo: (1) a relação (econômica, políca e social) das comunidades residentes com o seu território; (2) a intervenção de um agente externo no sentido de desmantelar os marcadores territoriais desses grupos e impor os seus; (3) criação de novos mecanismos de coesão identitária (adaptação) como reação a estes processos. Estes três elementos são pontos de partida

\footnotetext{
${ }^{6}$ Ser descendente de pai/ mãe africano/a e português/ esa não era condição sine qua non para que um indivíduo fosse considerado luso-africano. Muitos destes indivíduos eram descendentes de africanos ou europeus.
} 
para colocar questões ao registo arqueológico e às fontes escritas da Proto-história peninsular.

Os marcadores territoriais são elementos fundamentais para a construção da percepção do espaço ocupado, dominado ou percorrido por uma comunidade (HENRIQUES, 2004: 22-29; ALBUQUERQUE, 2014: 83). São instrumentos importantes para a construção de identidades coletivas, simbolizando uma relação de pertença com o território e, por conseguinte, com a imagem histórica de um grupo humano, ao torná-la visível. No âmbito peninsular, do ponto de vista arqueológico, tanto as necrópoles como os edifícios de culto de feição oriental podem desempenhar essa função de novos "discursos" implantados no território. A integração destes processos no contexto das relações entre grupos pode ser questionada nesse sentido, sobretudo se ditas construções simbolizam a imposição de uma nova ideologia dominante ou uma diferença significativa relativamente ao panorama anterior (padrões de fixação, de implantação destas estruturas, arquitetura). A reação a estas situações terá sido, como seria de esperar, diversificada, mas os objetivos da construção destes marcadores podem ser os mesmos.

Estes processos de territorialidade não se esgotam na implantação de estruturas. Admitindo que um edifício de culto se destina à organização e exploração do território, o fato de ser implantado num lugar dominante na paisagem pode significar que aqueles que o construíram pretendiam dar uma maior visibilidade à sua presença e à sua pertença. Isto pode implicar a anulação dos sistemas "indígenas" em prol de novas "lógicas civilizacionais" (para utilizar as palavras de I.C. HENRIQUES, 2004), sociais e até econômicas, estimulando, por sua vez, a existência de conflitos e relações de domínio ou dependência (MORENO, 1999; WAGNER, 2005: 178ss.; HENRIQUES, 2004: 14-15; ARRUDA, 2010: 448). O agente externo, num primeiro momento, pode ser visto como aquele que não tem qualquer relação de pertença prévia com um espaço (não tem os seus mortos ali enterrados), e isso pode ser determinante para identificar processos de violência, ou mesmo para justificar a importância da construção ou recuperação de relatos heróicos e de fundação que legitimam uma nova ocupação e a ideologia que lhe está subjacente ${ }^{7}$.

\footnotetext{
${ }^{7}$ Veja-se, nesse sentido, os artigos de Cruz Andreotti (1991) e Franzen (2009) sobre a importância da Gerioneida para o discurso sobre a colonização de Himera; Estrabão (3.5.5) transmitiu o relato de fundação de Gadir, mas não é prudente afirmar que o relato diz respeito a um período mais antigo. Sobre a antiguidade de Gadir, cf. Albuquerque, 2014: 102ss. Infelizmente, não se conhecem relatos de fundação de períodos mais recuados para a Península lbérica, e os que foram transmitidos são muito tardios (p.ex., Gárgoris e Habis, em Justino, 44). Não serão, por essa razão, considerados nesta reflexão.
}

\begin{tabular}{|l|l|l|l|l|l|l|}
\hline (C) Rev. Arqueologia Pública & Campinas, SP & v.9 & N$^{\circ} .1(11)$ & p.73-97 & Jan-Jun/2015 & ISSN 2237-8294
\end{tabular}


Antes de comentar os possíveis reflexos arqueológicos destes processos, vale a pena trazer à colação alguns textos que testemunham este tipo de comportamento, sobretudo em ocasiões de transição entre ideologias dominantes. O texto de Dt. 12.1-3 (sécs. V - IV a.C.) ${ }^{8}$ transmite a mentalidade subjacente ao comportamento atribuído a Josias no AT (2Rs. 23.1-20), do qual podemos citar algumas pequenas passagens para apoiar estas afirmações:

(15) Destruiu, igualmente, o altar de Betel e o lugar alto que edificara Jeroboão, filho de Nabat, que fez pecar Israel. Destruiu-os, queimou e reduziu a cinzas o lugar alto, incendiando igualmente o tronco de Achera. (16) Josias viu em torno de si os sepulcros que havia na colina; mandou tirar os ossos dos sepulcros e queimou-os no altar, profanando-o, segundo a palavra que o Senhor pronunciara pelo homem de Deus que anunciou estas coisas. (17) E o rei perguntou: "que monumento é esse que vejo?" Os habitantes da cidade responderam-lhe: "é o sepulcro do homem de Deus, que veio de Judá, e anunciou tudo o que fizeste ao altar de Betel." (18) Então, o rei disse: "deixai em paz os seus ossos". E os seus ossos ficaram intactos, juntamente com os ossos do profeta que viera da Samaria.

Devemos salientar que o percurso histórico dos reis de Israel e Judá é apresentado com o filtro deuteronomista elaborado a partir das reformas de Josias (640 - 609 a.C.), estruturando-se em torno do respeito ou desrespeito pela Aliança. É, por isso, natural que esta imagem seja um reflexo dessa mentalidade. Em todo o caso, não deixa de ser interessante verificar que a imposição de uma nova ideologia atinge elementos que se materializaram na paisagem, como é o caso dos versículos 16 e 17, preservando outros que serviriam de instrumentos de memória.

Olhando para outros contextos, voltamos a identificar o mesmo tipo de situação. Tanto Heródoto (1.64.2) como Tucídides (1.8.1) descreveram a "purificação" de Delos, que consistiu na destruição de sepulturas, sobretudo daquelas que estavam no raio de visão do santuário. Os rituais fúnebres destas sepulturas conduziram os profanadores a identificá-las com os Cários, indicando que o comportamento perante a morte foi um critério fundamental para a representação das comunidades, pelo menos em obras como a de Heródoto (cf. SOARES, 2003: passim). A destruição destas necrópoles pode ser, neste sentido, um indicador seguro da sua importância enquanto marcador territorial ou enquanto instrumento

\footnotetext{
8 "Eis as leis e os preceitos que devereis pôr em prática na terra que o Senhor, Deus de vossos pais, vos deu em propriedade; guardai-os todos os dias da vossa vida.Destruí todos os santuários, em que os povos, por vós desalojados, tiverem prestado culto aos seus deuses, nos altos montes, nas colinas e debaixo das árvores frondosas. Derrubai os altares, quebrai os monumentos, queimai os bosques sagrados e abatei as imagens dos deuses; fazei desaparecer daquela terra a sua lembrança."
}

\begin{tabular}{l|l|l|l|l|l|l|} 
(C) Rev. Arqueologia Pública & Campinas, SP & v.9 & N $^{\circ} 1(11)$ & p.73-97 & Jan-Jun/2015 & ISSN 2237-8294
\end{tabular}


na construção da imagem histórica de um grupo humano (cf. Od. 24.80-84 e a visibilidade dos túmulos; ALBUQUERQUE, 2014: 224ss).

O papel dos marcadores territoriais está bem patente na memória do templo de Salomão, construído por Hiram (cf. 1Rs. 6.1-22), ou mesmo na representação dos chamados "lugares altos" no AT (ALBUQUERQUE, 2014: 157-158, com textos e bibliografia). Poderíamos acrescentar outros exemplos que testemunham a funcionalidade destas estruturas na construção e manutenção de identidades de grupos (ibid:: 85-86) e que permitem, de certo modo, enquadrar os fenômenos que, arqueologicamente, são identificáveis na Península Ibérica, sobretudo no âmbito da suposta transição entre a Idade do Bronze e a Idade do Ferro (onde, aliás, se coloca a tônica da consolidação da "sociedade tartéssica").

Atendendo ao caso angolano, assiste-se à africanização das novidades europeias a vários níveis, após um processo de desenvolvimento de atividades comerciais. Numa primeira fase, os Portugueses comercializavam produtos com as autoridades africanas, sem qualquer tipo de instalação no seu território; posteriormente, solicitavam autorização para construir uma aldeia nas proximidades de um aglomerado populacional, separada e independente, antecedendo a terceira fase: convergência e reorganização de espaços comerciais. A última implicava a destruição das casas comerciais africanas e a instalação efetiva de Portugueses (HENRIQUES, 2000: 77). A degradação do poder destas elites foi, neste sentido, evidente, sobretudo quando se assistiu à implantação de novas estratégias de territorialidade.

A construção das colônias europeias implicou também o desenvolvimento de estudos que pretenderam dar a conhecer as populações que viviam dentro das fronteiras definidas pelo "Branco" e que resultaram na elaboração dos chamados mapas étnicos. A individualização destas "etnias" é, como demonstraram J.L. Amselle e E. M'Bokolo (1999; MORET, 2004), uma construção colonial que acabou por ser assumida, ou apropriada, por esses grupos. Assinale-se que as designações das comunidades procuraram obedecer aos critérios do observador e que as informações nem sempre eram diretas (ESTERMANN, 1983: 18ss.; ALBUQUERQUE, 2014: 56ss.). Os resultados destes estudos permitem defender, com E. Crowley (1993: 280-284), que os grupos humanos podem identificar-se a partir de quatro vias distintas: (1) nome de auto-designação; (2) nome utilizado pelos vizinhos; (3) nome que um terceiro elemento, diferente de 1 e 2 (viajante, comerciante, etc.) atribui ao grupo e (4) nome transmitido pelos informadores de 3 (cf. Plin., N.H. 4.120, com um exemplo nesse sentido). 


\section{5. "COMPARAR O INCOMPARÁVEL"? ALGUMAS CONSIDERAÇÕES FINAIS}

As últimas afirmações podem ser transpostas para a análise de Tartessos. Atendendo ao caráter extremamente vago das fontes, bem como ao fato de estarmos perante informações obtidas indiretamente, não é possível identificar com rigor em qual das quatro situações podemos integrar os textos que foram expostos. Como tal, a análise da etnogênese "tartéssica" ou dos seus mecanismos de identificação/individuação, vê-se extremamente comprometida, sobretudo quando as atenções se concentram na hermenêutica das fontes.

E em relação ao registo arqueológico? A representação arqueológica de Tartessos nasceu, como vimos, da convicção de que este nome designava as comunidades indígenas que se desenvolveram exponencialmente com o comércio com os Fenícios. Tal perspectiva pode ser desafiada por outros olhares que valorizam não só a componente oriental (cf. ÁLVAREZ, 2005; 2007; 2009, etc.), mas também a violência subjacente a processos desta natureza (MORENO ARRASTIO, 1999; 2000; 2001; WAGNER, 2005; ALBUQUERQUE, 2014). A comparação com outros exemplos históricos permite destacar algumas semelhanças e diferenças mas é, principalmente, um ponto de partida para analisar os contatos entre grupos orientais e residentes em termos de construção de novas percepções territoriais e de novos sistemas de exploração do meio envolvente. Estas situações têm, como parece óbvio, impactos sociais que nem sempre são valorizados pela investigação.

Vejamos um exemplo. No Castro dos Ratinhos, construiu-se um edifício de planta ortogonal que contrasta com as restantes estruturas de planta circular e que pode ser interpretado como um edifício de culto (BERROCAL e SILVA, 2010; ALBUQUERQUE, 2014: 188ss., com bibliografia). Foi implantado, nos finais do séc. IX a.C., sobre estruturas prévias cuja importância parece ser incontestável e parece ter ditado a última fase de ocupação deste núcleo habitacional. Curiosamente, a implantação deste edifício coincidiu com o desmantelamento dos sistemas de povoamento do Bronze Final nesta região alentejana. A destruição do edifício em c. 730 a.C. (note-se: somente do edifício) antecedeu o abandono definitivo dos Ratinhos alguns anos mais tarde, e permite entrever a importância destas estruturas enquanto elementos visíveis de identificação de um grupo possivelmente minoritário no contexto daquela ocupação. Não sabemos até que ponto dita construção resulta de relações de dependência (p.ex., 1Rs. 16. 31-33) ${ }^{9}$, de uma opção

${ }^{9}$ E, como se não Ihe bastasse imitar os pecados de Jeroboão, filho de Nafat, [Acab] ainda tomou por esposa Jezabel, filha de Etbaal, rei de Sídon; e foi prestar culto a Baal, prostrando-se diante dele. Ergueu um altar a Baal no templo de Baal, que construiu em Samaria. Acab fez também uma Achera, 
"indígena" no sentido de utilizar uma linguagem de poder externa ou da presença de um grupo exógeno ${ }^{10}$. Esta situação sugere, mais do que uma porta aberta ao progresso trazido pelo comércio e pelo consumo de bens de prestígio, que se trata de um comportamento que se reproduziu um pouco por todo o Sudoeste da Península lbérica, caracterizado pala implantação de novos marcadores.

As fontes dão algumas achegas a esta discussão e são suficientemente claras para que seja possível defender a reprodução destes processos em âmbito peninsular. Outros edifícios, com a mesma funcionalidade, mas com cronologia posterior, foram implantados junto a vias de circulação marítima, fluvial e terrestre de grande importância, maioritariamente em posição de domínio (excepto Cancho Roano e Abul) ${ }^{11}$. Nestes casos, não é coerente valorizar a função religiosa destes marcadores territoriais em detrimento do seu papel enquanto símbolos de poder econômico e político. Ou seja, o estudo destas estruturas é uma aproximação às relações entre grupos e destes com o território envolvente e com os circuitos nos quais se inserem, mais do que elementos que proporcionam um melhor conhecimento da religião.

Parece evidente, não obstante as dificuldades no acesso a um melhor conhecimento da religião dita "fenícia" (entre outros, MARíN, 2011), que estes edifícios eram autênticos "centros de sabedoria", detendo um papel importante na construção da memória coletiva enquanto transmissores de tradições (MARÍN e JIMÉNEZ, 2004; 1Sm. 31.8; Hdt. 2.44 e Str. 3.5.5. sobre a fundação de Tiro e Gadir, respectivamente). No caso que nos ocupa, é, talvez, inocente afirmar que os grupos que se instalaram nos territórios peninunsulares eram homogêneos, do mesmo modo que os "indígenas" com os quais contataram. A interpenetração é, neste contexto, inevitável e pode dar início a novas realidades culturais muito diferentes daquelas que, num primeiro momento, se encontraram (cf. BERNAND e GRUZINSKI, 2007: passim). Como tal, insistir na ideia de que Tartessos é

aumentando a ira do Senhor, deus de Israel, mais do que todos os reis de Israel, seus predecessores (1Rs. 16.31-33)

10 Podemos, neste sentido, questionar até que ponto é possível defender a transmissão de informações relativas ao culto sem a presença direta dos seus praticantes ou sem um bom conhecimento de uma suposta língua "estrangeira" (intérpretes?).

${ }^{11}$ Baía de Cádiz: santuário de Melqart, mencionado pelas fontes e não detetado arqueologicamente. Guadalquivir: Caura (Coria del Río); El Carambolo (Hispalis/Sevilha); Carmo (Carmona); Montemolín (Marchena, nas margens do Corbones); Tinto/ Odiel: Méndez Núñez, Huelva; Ilha de Saltés. Guadiana: Castro Marim; Ratinhos; Cancho Roano. Balsa (Tavira); Promontório Sacro?; Sado: Abul; Alcácer do Sal. Não se conhecem, até ao momento, edifícios com esta funcionalidade nas margens do Tejo (ALBUQUERQUE, 2014: 148ss. e respectiva bibliografia).

\begin{tabular}{|l|l|l|l|l|l|l|}
\hline (C) Rev. Arqueologia Pública & Campinas, SP & v.9 & N $^{\circ} .1(11)$ & p.73-97 & Jan-Jun/2015 & ISSN 2237-8294
\end{tabular}


uma entidade "puramente" indígena e diferenciada dos "Fenícios", com os quais mantiveram relações estritamente comerciais e independentes ao longo de vários séculos, pode turvar a visão de quem procura explicar a eclosão de elementos orientais nos enterramentos, na planta dos edifícios, nas técnicas de produção de cerâmicas, na alimentação e em vários elementos identificados no interior das construções dedicadas ao culto (pisos vermelhos, pavimentos de conchas ou altares taurodérmicos) ${ }^{12}$.

A construção de novos marcadores territoriais assinalaria, portanto, uma ruptura e não uma continuidade, como é constatável noutros contextos históricos, nomeadamente a colonização portuguesa em Angola, ou mesmo em São Jorge da Mina, no atual Ghana. Neste último caso, a fundação da feitoria teve o efeito de dar início a várias mudanças no modus vivendi das comunidades vizinhas, ou mesmo das que estavam no interior, uma vez que foi possível, com o comércio marítimo, um incremento da quantidade de produtos e, com este, a reorientação das rotas comerciais preexistentes (cf. DECORSE, 2001: 142). Conduziu, igualmente, ao desenvolvimento do comércio de escravos e à deslocação de populações em busca de outras condições de vida ${ }^{13}$. Em termos de registo material, registou-se uma grande variedade de produtos europeus e africanos que são resultantes do comércio, mas o fato de se verificar uma transformação evidente a partir da colonização efetiva destes territórios (ibid.: passim) é, por si só, um dado que deve ser considerado com muita atenção para a abordagem que pautou esta reflexão.

Dispomos, portanto, de dois tipos de fontes: os textos da Antiguidade e o registo arqueológico. Em muitos casos, assistimos a um (escusado) desencontro entre estas disciplinas, a tal ponto que cada uma delas pode utilizar informações e métodos da outra que já não fazem sentido nos dias de hoje, sem o necesário aparato crítico. Esta relação não pressupõe que se ressuscite o fantasma histórico-culturalista no sentido de analisar a cultura material para definir as fronteiras de um povo mencionado nas fontes escritas. Podemos, isso sim, questionar, através da comparação, o alcance das designações étnicas, das representações do "outro", os ecos dos contatos interculturais, a importância dos marcadores territoriais e o efeito por vezes violento da imposição de novas ideologias dominantes. Tartessos é, com toda a evidência, um desses casos.

Podemos dizer, em jeito de conclusão, que a comparação é um caminho de investigação viável para a discussão da "questão tartéssica" e dos processos de

\footnotetext{
${ }^{12}$ Sobre estes altares, vid. os contributos de A. Gómez Peña (entre outros, 2010).

13 O tema de S. Jorge da Mina foi desenvolvido noutra ocasião, dentro desta perspectiva comparativa.
} 
transformação identificáveis no registo arqueológico. Apesar de todas as diferenças, a presença europeia na África na Idade Moderna, comparada com a oriental no Ocidente no ocaso do Bronze Final, permite colocar novas questões sobre o efeito destes contatos no quotidiano dos intervenientes destes processos, bem como identificar cenários de violência onde, antes, se viam pacíficos contatos comerciais e a transformação levada a cabo por elites fascinadas com o "progresso" que esse comércio trazia. Sabemos, porém, que a realidade da colonização foi bem menos benévola.

\section{REFERÊNCIAS BIBLIOGRÁFICAS}

AAVV. Tartessos y Sus Problemas: V Symposium Internacional de Prehistoria Peninsular, Jerez de la Frontera, Septiembre 1968. Jerez de la Frontera: Ayuntamiento de Jerez de la Frontera, 1969, 437p.

Tartessos: entre mitos e representações (Cadernos da Uniarq, 6). Lisboa: Uniarq/ Universidade de Lisboa, 2010, 142p.

. Tartessos e Tartéssios, de Estesícoro a Éforo. In: Arnaud, J. M.; Martins, A.; Neves, C (eds.). Arqueologia em Portugal: 150 anos. Actas do I Congresso da Associação dos Arqueólogos Portugueses. Lisboa: Associação dos Arqueólogos Portugueses, p. 633-639, 2013.

Tartessos: a construção de identidades através do registo escrito e da documentação arqueológica. Um estudo comparativo. Lisboa: Universidade de Lisboa. Tese de Doutorado. Programa de pós graduação em Arqueologia e História, Universidade de Lisboa, Lisboa, 2014.

ÁLVAREZ MARTÍ - AGUILAR, M. Tarteso: la construcción de un mito en la historiografía española. Málaga: CEDMA, 2005, 262p.

Arganthonius Gaditanus: la identificación de Gadir y Tartessos en la tradición antigua. Klio, Berlim: n. 89 (2), p. 477 - 492, 2007.

Identidad y Etnia en Tartessos. Arqueología Espacial,

Zaragoza: n. 27, p. 79-111.

\begin{tabular}{|l|l|l|l|l|l|l|} 
(C) Rev. Arqueologia Pública & Campinas, SP & v.9 & No.1(11) $^{\circ}$ & p.73-97 & Jan-Jun/2015 & ISSN 2237-8294
\end{tabular} 
AMORES CARREDANO, F. Carta Arqueológica de los Alcores. Sevilha: Diputación Provincial de Sevilla, 1982, 293p.

AMSELLE, J.-L.; M'BOKOLO, E. (dirs.), Au coeur de l'ethnie. Anthropologie de I'Identité en Afrique et ailleurs. Paris: Payot, 1999, 227p.

AUBET SEMMLER, M. ${ }^{a}$ E. Los marfiles fenicios del Bajo Guadalquivir. 1. Cruz del Negro. Boletín del Seminario de Estudios de Arte y Arqueología. Valladolid: n. 44, p. 15 - 77, 1978. . Horizonte cultural protohistórico. Revista de Arqueología. Madrid:

n. Extra, 1, p. 58-73.

BELÉN DEAMOS, M.a-; ESCACENA CARRASCO, J.L. Testimonios religiosos de la presencia fenicia en Andalucía Occidental. Spal. Sevilha: n. 6, p. 103-131.

BERNAND, C.; GRUZINSKI, S. Histoire du Nouveau Monde, vol. II, Les Métissages. Paris: Fayard, 2007, 791p.

BERROCAL-RANGEL, L.; SILVA, A.C. O Castro dos Ratinhos (Barragem do Alqueva, Moura). Escavações num povoado proto-histórico do Guadiana, 2004-2007. (Suplemento de 0 Arqueólogo Português, 6) Lisboa, Museu Nacional de Arqueologia, 2010, 469p.

BONSOR, G. Las Colonias agrícolas prérromanas del Valle del Guadalquivir. Écija: Gráficas Sol, 1997, 190p.

CAMPOS CARRASCO, J.; ALVAR EZQUERRA, J., eds. Tarteso: el Emporio del Metal. Córdoba: Almuzara, 736

CARRIAZO Y ARROQUÍA, J.M. Protohistoria de Sevilla. Sevilha, Ediciones Guadalquivir, 1980, 434p.

CARRIAZO Y ARROQUÍA, J.M.; RADDATZ, K. Primicias de un corte estratigráfico en Carmona. Archivo hispalense. Sevilla: n. 33 (103-104), p. 333-369, 1960. 
CROWLEY, E.L. Contracts with spirits: Religion, Asylum and Ethnic Identity in the Cacheu region of Guinea - Bissau. Michigan: UMI Dissertations/ A Bell e Howell Company, 1993, 727p.

CRUZ ANDREOTTI, G. Estesícoro y Tartessos. Habis, Sevilha: n. 22, p. 49-62, 1991

DECORSE, C.R. An Archaeology of Elmina: Africans and Europeans on the Gold Coast, 1400 - 1900. Washington DC: Smithsonian Institution Press, 2001, 286p.

ESCACENA CARRASCO, J.L. La etapa precolonial de Tartessos. Reflexiones sobre el "Bronce" que nunca existió. In: AAVV, Tartessos 25 años después (1968 - 1993). Jerez de la Frontera: Ayuntamiento de Jerez de la Frontera, p. 179-214, 1995

ESTERMANN, C. Etnografia de Angola (Sudoeste e Centro). Colectânea de artigos dispersos, coligidos por G. Pereira e apresentados por M.V. Guerreiro, vol. 1, Lisboa: Instituto de investigação científica tropical, 1983, 483p.

FRANZEN, C. Sympathizing with the Monster: Making sense of Colonization in Stesichorus' Geryoneis. Quaderni Urbinati di Cultura Clasica. Nova Série, 92, p. 55-72, 2009.

GARCÍA FERNÁNDEZ, F.J. Tartesios, Túrdulos, Turdetanos. Realidad y ficción de la homogeneidad étnica de la Bética Romana. In: Santos Yanguas, J.; Cruz Andreotti, G. (eds.), Romanización, fronteras y etnias en la Roma Antigua: el caso hispano (Revisiones de Historia Antigua, VII). Victoria/ Gasteiz: Universidad del País Vasco, p. 691-734, 2012.

GÓMEZ PEÑA, A. Así en Oriente como en Occidente: el origen oriental de los altares taurodérmicos de la Península Ibérica. Spal. Sevilha: n.19, p. 129-148, 2010.

GONZÁLEZ DE CANALES, F. Del Occidente mítico a Tarsis - Tarteso. Madrid: Biblioteca Nueva, 425p.

HENRIQUES, I.C. Comércio e organização do espaço em Angola (c. 1870 - 1950), in: Santos, M.르.M. (dir.), A África e a instalação do sistema colonial (c. 1885 - c. 1930). III 
Reunião Internacional de História de África. Lisboa: Centro de Estudos de História e Cartografia Antiga/ Instituto de Investigação Científica Tropical, p. 71-90, 2000

Território e Identidade. Lisboa: Centro de História da Faculdade de Letras da Universidade de Lisboa, 2004.

HORTA, J.S. Entre história europeia e história africana, um objecto de charneira: as representações. In: AAVV, Colóquio Construção e Ensino da História de África: Actas das sessões realizadas na fundação Calouste Gulbenkian nos dias 7, 8 e 9 de Junho de 1994. Lisboa: Grupo de Trabalho do Ministério da Educação para as Comemorações dos Descobrimentos Portugueses, p. 181-200, 1995

Ser "Português" em terras africanas: vicissitudes da construção identitária na "Guiné do Cabo Verde" (sécs. XVI - XVII). In: Matos, S.C.; Henriques, I.C.; Fernandes, H.; Horta, J.S., eds. - Nação e Identidades. Portugal, os portugueses e os outros. Lisboa: Centro de História da Faculdade de Letras de Lisboa/ Caleidoscópio, p. 261-274, 2009

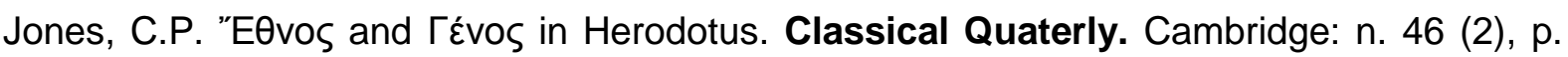
315-320.

$\mathrm{KOCH}, \mathrm{M}$. Tarsis e Hispania. Estudios histórico-geográficos y etimológicos sobre la colonización fenicia de la Península Ibérica. Madrid: CEFYP, 2003, 276p.

MALUQUER DE MOTES, J. El proceso histórico de las primitivas poblaciones peninsulares II. Zephyrvs, Salamanca: n. 6, p. 241-283, 1955.

MARÍN CEBALLOS, M. ${ }^{a}$ C. En torno a las fuentes para el estudio de la religión fenicia en la Península Ibérica. In: Marín Ceballos, M. ${ }^{a}$ C. (coord.), Cultos y ritos de la Gadir fenicia. Cádiz: SPUC, p. 15-43, 2011.

MARÍN CEBALLOS, M.ํㅡ C.; JIMÉNEZ FLORES, A.M.른 Los santuarios fenicio-púnicos como centros de sabiduría: el templo de Melqart en Gadir. Huelva Arqueológica. Huelva: n.20, p. 215-239, 2004.

MCINTOSH, S.K. Tools for understanding transformation and continuity in Senegambian Society: 1500-1900. In: DeCorse, C. R. (ed.), West Africa during the Atlantic Slave \begin{tabular}{|l|l|l|l|l|l|l|} 
(C) Rev. Arqueologia Pública & Campinas, SP & v.9 & N$^{\circ} .1(11)$ & p.73-97 & Jan-Jun/2015 & ISSN 2237-8294
\end{tabular} 
Trade: Archaeological Perspectives. London, New York: Leicester University Press, p. 1437,2001

Mederos Martín, A. Fenicios en Huelva, en el siglo X a.C., durante el reinado de Hiram I de Tiro. Spal. Sevilla: n.15, p. 167-188, 2006.

METZGER, H. BRIGITTE FREYER SCHAUENBURG, Elfenbeine aus dem samischen Heraion, "abhandlungen aus dem Gebiete der Auslanskunde" [...]. Syria. Paris: n. 44 (3-4), p. $433-436,1967$

MORENO ARRASTIO, F.J. Conflictos y perspectivas en el periodo precolonial tartésico. Gerión, Madrid: n. 17, p. 149-177.

Tartessos, Estelas, Modelos Pesimistas. In: Uriel, P.; Wagner, C.G.; López Pardo, F. (eds.), Intercambio y Comercio preclásico en el Mediterráneo, Madrid: CEFYP, p. $153-174,2000$

Sobre anomalías e interpretación de los objetos orientalizantes en la Meseta. Gerión. Madrid: n. 19, p. 99-117, 2001

MORET, P. Ethnos ou Ethnie? Avatars anciens et modernes des noms des peuples ibères. In: Cruz Andreotti, G.; Mora Serrano B. (eds.) Identidades étnicas - identidades políticas en el mundo prerromano hispano. Málaga: CEDMA, p. 32-62, 2004

OLMOS ROMERA, R. Los griegos en Tartessos: una nueva contrastación entre las fuentes arqueológicas y las literarias. In: Aubet Semmler, M. ${ }^{a}$ E. (coord.), Tartessos: Arqueología protohistórica del Bajo Guadalquivir. Sabadell: Ausa, p. 495-521, 1989

PAGE, D.L. Stesichoros: The Geryonëis. Journal of Hellenic Studies. Cambridge: n. 93, p. 138-154, 1973

PELlicer CATAlÁN, M.; AmORES CARREdANO, F. Protohistoria de Carmona. Los cortes estratigráficos CA80/A y CA-80/B. Noticiario Arqueológico Hispánico. Madrid: n. 22, p. 55-190, 1985 
SANMARTÍN, J. Toponimia y antroponimia: Fuentes para el estudio de la cultura púnica en España. In: González Blanco, A.; Cunchillos Ilarri, J.L.; Molina Matos, M. (coords.) EI mundo púnico. Historia, sociedad y cultura. Murcia: Editora regional de Murcia, p. 227247, 1994

SCHEPENS, G. Historiographical problems in Ephorus. In: Historiographia Antiqua: Commentationes Lovanienses in Honorem W. Peremans Septuagenarii Editae. Leuven: Leuven University Press, p. 95-118, 1977.

SCHULTEN, A. Tartessos. $2^{\underline{a}}$ ed. Madrid: Espasa - Calpe, 1945, 296p.

SOARES, C.L. A Morte em Heródoto: Valores universais e particularismos étnicos. Lisboa: Fundação Calouste Gulbenkian, 2003, 544p.

TORRES ORTIZ, M. Tartessos. Madrid: Real Academia de Historia, 2002, 477p.

¿Una colonización tartésica en el interfluvio Tajo - Sado en la Primera Edad del Hierro? Revista Portuguesa de Arqueologia. Lisboa: n.8 (2), p. 193-213.

WAGNER, C.G. WAGNER, C.G. Fenicios en el Extremo Occidente. Conflicto y violencia en el con-texto colonial arcaico. Revista Portuguesa de Arqueologia. Lisboa: n. 8 (2), p. 177192. 